\title{
Sıvılaşmanın UBC3D-PLM Model ile Tahmin Edilmesi: Santrifüj Deneyi Örneği
}

\author{
Selçuk DEMİ ${ }^{1}$ \\ Pelin ÖZENER ${ }^{2}$
}

ÖZ

Bu çalışmada UBC3D-PLM model ile literatürde yer alan santrifüj deneyi modellenerek elde edilen sonuçlar deneysel ve sayısal olarak karşılaştırılmış ve sıvılaşma davranışı tahmin edilmeye çalışılmıştır. İlk olarak UBC3D-PLM model için gereken malzeme parametreleri ve kalibrasyon aşamalarından bahsedilerek santrifüj model deneyinde kullanılan zeminlerin monotonik ve çevrimsel yükler altındaki davranışı, sayısal modelde benzer bir davranış sergileyecek şekilde kalibre edilmiştir. Kalibrasyon sonucunda elde edilen malzeme parametreleri kullanılarak, santrifüj deneyi sayısal olarak modellenmiştir. Sayısal analiz sonucunda hesap edilen ivme, artık boşluk suyu basıncı ve deplasmanlar deneyde ölçülen değerler ile karşılaştırılmış, sıvılaşma başlangıcı ile boşluksuyu basıncı oluşumu ve ivmeler açısından tutarlı sonuçlar elde edilmiştir. Ancak, artık boşluk suyu basınçlarının sönümlenmesi ve dolaylı olarak deplasman seviyelerinde istenilen tutarlılık elde edilememiştir.

Anahtar Kelimeler: UBC3D-PLM, UBCSAND, sıvılaşma, sayısal analiz.

\section{ABSTRACT \\ Estimation of Liquefaction with UBC3D-PLM Model: A Centrifuge Test Example}

In this study, a centrifuge test presented in the literature is numerically modeled with UBC3D-PLM model and obtained results are compared experimentally and numerically to predict liquefaction behavior. First, the material parameters and calibration steps required for the UBC3D-PLM model are mentioned and the behavior of the soils used in the centrifuge model test under monotonic and cyclic loads is calibrated to represent a similar behavior in the numerical model. By using the material parameters obtained from the calibration, the centrifuge experiment is numerically modelled. As a result of the numerical analysis, the

\footnotetext{
Not: $\mathrm{Bu}$ yazı

- Yayın Kurulu'na 28 Şubat 2018 günü ulaşmıştır. 9 Ekim 2018 günü yayımlanmak üzere kabul edilmiştir.

- 30 Kasım 2019 gününe kadar tartışmaya açıktır.

- https://dx.doi.org/10.18400/tekderg.399574

1 Bolu Abant İzzet Baysal Üniversitesi, İnşaat Mühendisliği Bölümü, Bolu - seljukdemir4071@gmail.com https://orcid.org/0000-0003-2520-4395

2 Yıldız Teknik Üniversitesi, İnşaat Mühendisliği Bölümü, İstanbul - tohumcu@yildiz.edu.tr https://orcid.org/0000-0002-9407-286x
} 
computed excess pore water pressure, acceleration and displacements are compared with the values measured in the experimental study and consistent results are obtained in terms of onset of liquefaction, excess pore water pressure development, and time history of accelerations. However, similar responses are not obtained from excess pore pressure dissipation and displacement results.

Keywords: UBC3D-PLM, UBCSAND, liquefaction, numerical analysis.

\section{GíRiş}

Ani gelişen doğal afetler (deprem, sel, toprak kaymaları, hortum, volkan patlamaları vb.) toplumlar üzerinde ekonomik, sosyolojik ve psikolojik açıdan uzun süre devam edebilecek olumsuz etkiler bırakabilmektedir. Bu afetler arasında yer alan depremlerde kendi içerisinde bir bölgeye veya bir yapıya farklı şekillerde hasar verebilmekte, can ve mal kayıplarına neden olabilmektedir. Depremlerin neden olduğu ve sismik felaketler olarak bilinen bu olgular genellikle yer hareketi, tsunami, zemin büyütmesi, sıvılaşma ve toprak kaymaları gibi çeşitli şekillerde karşımıza çıkmaktadır.

Dünyada her yıl çok sayıda deprem meydana gelmekte ve bunlardan bazıları can ve mal kaybına yol açacak ölçekte olmaktadır. Özellikle 1964 Niigata-Japonya ve Alaska-ABD depremi ile başlayan ve günümüze kadar devam eden güncel süreç incelendiğinde pek çok büyük ölçekli depremle beraber sıvılaşma ve sıvılaşmaya bağlı hasarların meydana geldiği görülmüştür [1]. Yakın zamanda 1999 yılında Kocaeli'nde meydana gelen sıvılaşma ve buna bağlı gelişen akmalar sonucu pek çok yapıda tahribat veya göçme meydana gelmiş, çok sayıda can ve mal kayıpları yaşanmıştır [2,3]. Ülkemizde Kocaeli depremi ile sıvılaşmanın ne kadar önemli bir konu olduğu ortaya çıkmıştır. Hasarların ve can kayıplarının bu denli büyük olması sıvılaşma mekanizması ile doğrudan ilişkilidir. Sıvılaşma, suya doygun gevşek kohezyonsuz zeminlerin dinamik yüklerin etkisi altında boşluk suyu basınçları artışına bağlı olarak, daneler arasındaki temas yüzeylerinin yok olması ve bunun neticesinde mukavemetlerini kaybederek bir sıvı gibi davranması olarak açıklanabilir. Bu olgu neticesinde yanal akma, taşıma gücü kaybı ve oturma problemleri, şev stabilite problemleri ve kum kaynamaları gibi sorunlar ortaya çıkabilmektedir $[4,5,6]$. Dolayısıyla, sıvılaşmanın engellenmesi veya etkilerinin tahmin edilip azaltılmaya çalışılması geoteknik ve deprem mühendisliği konuları arasında önemli bir yere sahiptir.

Son yıllarda pek çok araştırmacı sıvılaşma problemine yoğunlaşmış ve farklı özelliklerdeki bünye modellerinden faydalanarak sıvılaşma davranışını ve sıvılaşma sonrası oluşacak olumsuzlukların önüne geçebilmek adına çalışmalar gerçekleştirmişlerdir $[7,8,9,10,11,12$, 13]. Günümüzde, sıvilaşma tahmininde tercih edilen modellerden bir tanesi de Plaxis bünyesinde yer alan ve kullanıcı tanımlı bir model olan UBC3D-PLM modeldir.

Literatürde UBC3D-PLM model ile yapılan iki boyutlu (2D) çalışmalar incelendiğinde, Petalas ve Galavi (2013) ile UBC3D-PLM modelin kullanımı sürecinin başladığı söylenebilir [12]. Araştırmacılar yaptıkları çalışma ile modelin bünye bağıntıları hakkında detaylı bilgi vermişler, kalibrasyonu ve uygulamasına dair bir rapor ortaya koymuşlardır. Raporda ilk olarak, gevşek Syncrude kumu üzerinde laboratuvarda gerçekleştirilen drenajsız monotonik üç eksenli basınç deneyi (TXC) ve monotonik direkt basit kesme deneyi (DSS) sonuçlarını UBC3D-PLM model sonuçları ile karşılaştırmışlardır. Daha sonra UBC3D-PLM modelin çevrimli yükler altındaki sonuçlarını incelemişler ve [14] tarafından gevşek Fraser kumu 
üzerinde laboratuvarda gerçekleştirilen çevrimsel direkt basit kesme (CDSS) deney sonuçları ile sayısal analiz sonuçlarını kıyaslamışlardır. Sonuç olarak, monotonik ve çevrimsel yükler altında UBC3D-PLM modelin laboratuvar sonuçları ile tutarlı sonuçlar verdiğini bildirmişlerdir. Raporun son kısmında, [10] tarafından gerçekleştirilen bir santrifüj deneyini Plaxiste modelleyerek deney sonucunda elde edilen artık boşluksuyu basınçlarını UBC3DPLM model ile elde edilen sonuçlar ile karşılaştırmışlardır. Sonuçta UBC3D-PLM modelin düşük çevre basınçları altında oluşan artık boşluk suyu basınçlarını yüksek çevre basınçları altında oluşan artık boşluk suyu basınçlarına göre çok daha iyi modelleyebildiğini belirtmişlerdir.

Galavi vd. (2013) yaptıkları çalışmada, bir vaka analizi gerçekleştirmişler ve Japonya'nın Kobe ilinde yapılan bir rıhtım duvarını Plaxiste modellemişlerdir [15]. Model sonuçlarından duvarın üst köşe noktasının yapmış olduğu yatay ve düşey deplasmanların değişimini elde etmişler ve bu sonuçların arazi ölçümlerine göre rapor edilen deplasman aralıklarının içerisinde yer aldığını belirtmişlerdir. Ancak, arazide zamana bağlı bir deplasman ölçümü olmadığı için sadece sahadaki nihai deplasmanların sayısal modelden elde edilen nihai deplasmanlara yakın olduğunu belirtmişlerdir. Ayrıca modelin sınır koşullarını da değiştirerek, sınır koşullarının yatay deplasman değişimi üzerindeki etkisini incelemişlerdir.

Makra (2013) yapmış olduğu çalışmada UBC3D-PLM model ile Kaliforniya'da bulunan San Fernando barajını sayısal olarak modellemiş ve analizler sonucunda UBC3D-PLM modelinin sıvılaşma başlangıcını ne derecede modelleyebildiğini ve sıvılaşma sonrası deformasyonları tahmin edip edemediğini araştırmıştır [16]. Çalışma sonucunda modelin sıvılaşma başlangıcını modelleyebildiğini ancak, sıvılaşma sonrası davranışı iyi bir şekilde modelleyemediğini açıklamıştır.

Yukarıdaki çalışmalara ek olarak [17], [18], [19] tarafından yapılan araştırmalar ile UBC3DPLM model farklı geoteknik problemlerde kullanılarak modelin etkinliği incelenmiştir. Ayrica, Plaxis'in 2018 versiyonunda malzeme modeli kılavuzuna UBC3D-PLM model eklenerek, modelin kullanım ve kalibrasyonuna dair detaylı bilgiler vermiştir [20].

Bu çalışma kapsamında, literatür çalışmaları incelendiğinde analiz sonuçlarının genellikle artık boşluk suyu basınçları üzerinden incelendiği ve ivme-zaman ile deplasmanlar açısından çok detay verilmediği görülmektedir. Ayrıca yapılan çalışmalarda, artık boşluk suyu basınçlarında sönümün etkisi incelenmemiş UBC3D-PLM modelin boşluk suyu basıncı sönümlerini dikkate alıp almadığı detaylıca sorgulanmamıştır. Bu çalışmada ise Plaxis UBC3D-PLM model kullanılarak Rayamajhi vd. (2015) tarafından gerçekleştirilen model santrifüj deneylerinden sadece bir tanesi sayısal olarak modellenmiş ve elde edilen sonuçlar artık boşluk suyu basıncı, ivme ve deplasmanlar açısından incelenmiştir [21]. Sayısal analizlerin sonucunda elde edilen değerler ile laboratuvar verileri karşılaştırılarak yapılan sayısal analizlerin ve kullanılan UBC3D-PLM modelin kullanılabilirliği ortaya çıkartılmıştır. Modelin olumlu ve olumsuz tarafları detaylıca incelenerek, model kullanılırken dikkat edilmesi gereken noktalara değinilmiştir.

\section{UBC3D-PLM SIVILAŞMA BÜNYE MODELI}

UBC3D-PLM model, Plaxis'te sıvılaşma modellemede kullanılan ve kullanıcı-tanımlı özelliğe sahip bir bünye modelidir. Bu modelin temelini, ilk defa [8] ile [22] tarafindan 
tanıtılan ve orijinalinde UBCSAND olarak bilinen model oluşturmaktadır. UBCSAND, kumlu veya siltli kum zeminlerin sıvılaşma davranışını modelleyebilen elasto-plastik efektif gerilme modelidir. [12], [15] ve [23] UBCSAND model üzerinde geliştirmeler ve düzeltmeler uygulayarak UBC3D-PLM modelin son halini ortaya çıkarmışlardır.

Formülasyon olarak UBCSAND model, Duncan-Chang yaklaşımını ve modifikasyonlarını içermekle beraber klasik plastisite teorisi ve hiperbolik şekil değiştirme pekleşme kuralından oluşmaktadır [12]. Bununla beraber, UBC3D-PLM modelin formülasyonunu, DuncanChang yaklaşımını baz alan, modifiye edilmiş hiperbolik şekil değiştirme pekleşme kuralı ile klasik plastisite teorisini temel alan efektif gerilme modeli oluşturmaktadır. Ayrica, UBCSAND ile UBC3D-PLM arasındaki temel fark akma yüzeyini tanımlarken kullandıkları boyut farklılığıdır. UBCSAND model, bağımsız plastik potansiyel fonksiyon ve 2 boyutlu (2D) Mohr-Coulomb akma yüzeyini kullanıyorken, UBC3D-PLM ise Mohr-Coulomb akma durumunu 3 boyutlu (3D) asal gerilme uzayında kullanmaktadır [12]. Herhangi bir elastoplastik davranışı baz alan modelde olduğu gibi bu modelde de şekil değiştirmeler, elastik ve plastik olmak üzere iki kısımdan oluşmaktadır. Elastik bölgede davranış non-lineerdir ve elastik bulk modülü $\left(\mathrm{K}_{\mathrm{B}}^{\mathrm{e}}\right)$ ile elastik kayma modülüne $\left(\mathrm{K}_{\mathrm{G}}^{\mathrm{e}}\right)$ bağlı olarak gerçekleşir. Bu iki parametre gerilmelere bağımlı olarak şu denklemlerle ifade edilebilirler:

$$
\begin{aligned}
& \mathrm{K}_{\mathrm{B}}^{\mathrm{e}}=\mathrm{k}_{\mathrm{B}}^{\mathrm{e}} \mathrm{P}_{\mathrm{A}}\left(\frac{\mathrm{p}^{\prime}}{\mathrm{P}_{\mathrm{A}}}\right)^{\mathrm{me}} \\
& \mathrm{K}_{\mathrm{G}}^{\mathrm{e}}=\mathrm{k}_{\mathrm{G}}^{\mathrm{e}} \mathrm{P}_{\mathrm{A}}\left(\frac{\mathrm{p}^{\prime}}{\mathrm{P}_{\mathrm{A}}}\right)^{\mathrm{ne}}
\end{aligned}
$$

Burada, $\mathrm{K}_{\mathrm{B}}^{\mathrm{e}}$ ve $\mathrm{K}_{\mathrm{G}}^{\mathrm{e}}$ sırasıyla elastik bulk ve elastik kayma modülünü ifade etmektedir. $\mathrm{k}_{\mathrm{B}}^{\mathrm{e}}$ ve $\mathrm{k}_{\mathrm{G}}^{\mathrm{e}}$ ise atmosfer basıncı $\left(\mathrm{P}_{\mathrm{A}}=100 \mathrm{kPa}\right)$ değerindeki bulk ve kayma modülü sayılarıdır. $\mathrm{p}^{\prime}$ ortalama efektif gerilme, $m e$ ve $n e$ rijitliğe bağlı oran olarak belirlenen elastik üs indisleridir.

Eğer modelde gerilme durumu akma yüzeyine ulaşırsa plastik davranış kendini gösterir ve kalıcı deformasyonlar oluşmaya başlar. $\mathrm{Bu}$ durumda modelde asal pekleşme şekil değiştirmesini baz alan plastik pekleşme kullanılır. Başka bir deyişle, kayma mukavemetinin mobilizasyonu ( $\sin \phi_{\text {mob }}^{\prime}$ ) sonrasında model, plastik şekil değiştirmelerin miktarını dikkate alir.

3D akma yüzeylerinin karmaşıklığını modele yansıtabilmek için maksimum ve minimum gerilme bileşenlerinden oluşan ve Mohr-Coulomb göçme kriterini baz alan asal gerilmelerin 6 kombinasyonu, 3D asal gerilme uzayını yansıtması için modele tanımlanmıştır. $\mathrm{Bu}$ durumda oluşan akma yüzeyinin fonksiyonu şu şekilde ifade edilmektedir:

$\mathrm{f}_{\mathrm{m}}=\frac{\sigma_{\mathrm{maks}-}^{\prime} \sigma_{\mathrm{min}}^{\prime}}{2}-\left(\frac{\sigma_{\mathrm{maks}}^{\prime}+\sigma_{\mathrm{min}}^{\prime}}{2}+\mathrm{c}^{\prime} \cot \phi_{\mathrm{p}}^{\prime}\right) \sin \phi_{\text {mob }}^{\prime}$

$\sigma_{\text {maks }}^{\prime}$ ve $\sigma_{\text {min }}^{\prime}$ maksimum ve minimum asal efektif gerilmelere karşılık gelmektedir. $c^{\prime}$ ve $\phi_{p}^{\prime}$ ise sırasıyla zeminin kohezyonunu ve efektif pik içsel sürtünme açısını ifade etmektedir. [22] tarafından UBCSAND model için kullanılan pekleşme kuralı, [23] tarafından tekrar formüle edilerek hiperbolik pekleşme kuralı olarak UBC3D-PLM model içerisine yerleştirilmiştir. Yeniden formüle edilmiş model birincil ve ikincil olmak üzere iki akma yüzeyinden 
oluşmaktadır ve formülasyonu izotropik ve kinematik pekleşmeyi baz almaktadır. UBC3DPLM için pekleşme kuralı Denklem 4 kullanılarak ifade edilmektedir:

$\mathrm{d} \sin \phi_{m o b}^{\prime}=1.5 \mathrm{k}_{\mathrm{G}}^{\mathrm{p}}\left(\frac{\mathrm{p}^{\prime}}{\mathrm{P}_{\mathrm{A}}}\right)^{\mathrm{np}} \frac{\mathrm{P}_{\mathrm{A}}}{\mathrm{p}^{\prime}}\left(\frac{\sin \phi_{\mathrm{mob}}^{\prime}}{\sin \phi_{\mathrm{p}}^{\prime}} \mathrm{R}_{\mathrm{f}}\right)^{2} d \lambda$

Burada, $d \lambda$ plastik şekil değiştirme artış çarpanı, $R_{f}$ göçme oranı $\left(R_{f}<1\right), \mathrm{k}_{\mathrm{G}}^{\mathrm{p}}$ plastik kayma modülü sayısı ve $n p$ plastik kayma modülü indisidir.

Modelin plastik potansiyel fonksiyonu, Drucker-Prager bağımsız akma kuralını baz alarak plastik şekil değiştirmelerin oluşacağı yönü tanımlamaktadır [23]. Plastik potansiyel fonksiyon Denklem 5 ile ifade edilebilir:

$\mathrm{g}=\mathrm{q}-\mathrm{a}\left(\mathrm{p}^{\prime}+\mathrm{c}^{\prime} \cot \phi_{\mathrm{p}}^{\prime}\right)$

Burada, $\mathrm{q}=\sigma^{\prime}{ }_{1}-\sigma^{\prime}{ }_{3}$ ve a değeri Denklem 6'da gösterilen eşitlik ile hesaplanabilir:

$\mathrm{a}=\frac{\sqrt{3} \sin \psi_{\operatorname{mob}}}{\cos \theta+\frac{\sin \theta \sin \psi}{\sqrt{3}}}$

Denklemlerde yer alan $\sigma_{1}^{\prime}$ ve $\sigma_{3}^{\prime}$ asal gerilmeleri, $\psi$ dilatasyon açısını ve $\theta$ Lode açısını ifade etmektedir. $\sin \psi_{\text {mob }}$ değeri sabit hacim içsel sürtünme açısına $\left(\phi_{\text {cv }}^{\prime}\right)$ bağlı olarak aşağıdaki bağıntı yardımı ile elde edilebilir [22]:

$\sin \psi_{\mathrm{mob}}=\sin \phi_{\mathrm{mob}}^{\prime}-\sin \phi_{\mathrm{cv}}^{\prime}$

Akma kuralı olarak UBC3D-PLM model, orijinal UBCSAND modelin sahip olduğu akma kuralını kullanmaktadır. Modelde yer alan akma kuralı [24] tarafından geliştirilen gerilmegenleşme teorisini baz almaktadır ve neticede akma kuralı şu şekilde ifade edilebilir:

$\mathrm{d} \epsilon_{\mathrm{v}}^{\mathrm{p}}=\sin \psi_{\mathrm{m}} \mathrm{d} \gamma^{\mathrm{p}}$

Burada $d \epsilon_{v}^{p}$ ve $d \gamma^{p}$ sırasıyla plastik hacimsel şekil değiştirme artışını ve plastik kayma şekil değiştirmesi artışını ifade etmektedir.

Sıvılaşma esnasında oluşacak boşluk suyu basınçlarının daha iyi tahmin edilebilmesi için UBC3D-PLM modelin en son sürümüne zemin sıkılaşma kuralı (densification rule) tanımlanmıştır. Ayrıca zeminin sıvılaşmaya yumuşak bir şekilde geçiş yapabilmesini sağlayabilmek adına ikincil yükleme için ikincil akma yüzeyi modele eklenmiştir. İkincil akma yüzeyi, birincil akma yüzeyine göre daha az plastik şekil değiştirmelere neden olmaktadır. Birincil yükleme esnasında kullanıcı tarafından girilen plastik kayma modülü $\mathrm{K}_{\mathrm{G}}^{\mathrm{p}}$, birincil akma yüzeyinin pekleşmesinde kullanılmaktadır. Denklem 9'da verilen değer ikincil yükleme aşamasında ise $\mathrm{K}_{\mathrm{G}}^{\mathrm{p}}$ çevrim sayına bağlı olarak formüle edilmiş halidir ve bu değer ikincil yükleme esnasında zemin sıkılaşmasını yansıtması için her bir çevrim sayısına bağlı olarak artmaktadır [12]. 
$\mathrm{K}_{\mathrm{G}}^{\mathrm{p}}=\mathrm{K}_{\mathrm{G}, \text { birincil }}^{\mathrm{p}} *\left(4+\frac{\mathrm{n}_{\mathrm{rev}}}{2}\right) * h a r{ }^{*} f_{\text {achard }}$

$\mathrm{n}_{\mathrm{rev}}$, deney başlangıcından elde edilen yarım çevrim sayısı, hard gevşek zeminler için sıklaştırma doğrulama faktörü, $f_{\text {achard }}$ sıkılaşma kuralını ayarlayan ve 0-1 arasında değişen bir faktördür.

Gevşek granüler zeminlerdeki sıvılaşma sonrası davranışı ve rijitlik dağılımını modelleyebilmek için UBC3D-PLM modelde plastik kayma şekil değiştirmelerin fonksiyonu olan plastik kayma modülünün azalım miktarını dikkate alan bir kural tanımlanmıştır. Bu kural;

$\mathrm{K}_{\mathrm{G}}^{\mathrm{p}}=\mathrm{K}_{\mathrm{G}, \text { birincil }}^{\mathrm{p}} * \mathrm{e}^{\min \left(110 \epsilon_{\text {dil, }} \mathrm{f}_{\text {acpost }}\right)}$

olarak ifade edilmektedir. Burada $\epsilon_{\text {dil }}$ zemin elemanının genleşmesi sırasında oluşan plastik deviatörik şekil değiştirmelerin toplamı, $f_{\text {acpost }}$ zeminin sıvılaşma sonrası halindeki davranışını kontrol eden üssel bir faktördür.

UBC3D-PLM modelde drenajsız davranış sırasında boşluk suyu basınçlarının artışı,

$d p_{w}=\frac{K_{w}}{n} d \epsilon_{v}$

ile dikkate alınmaktadır. Burada $p_{w}$ boşluksuyu basıncını, $K_{w}$ suyun bulk modülünü, $n$ poroziteyi ve $\epsilon_{v}$ sıvının hacimsel şekil değiştirmesini ifade etmektedir. Bir zemin suya doygun olduğu durumlarda suyun bulk modülü Denklem 12 ile hesaplanabilir:

$\frac{K_{w}}{n}=K_{u}-K^{\prime}=\frac{2 K_{G}^{e}}{3}\left(\frac{1+v_{u}}{1-2 v_{u}}-\frac{1+v^{\prime}}{1-2 v^{\prime}}\right), v^{\prime}=\frac{3 K_{B}^{e}-2 K_{G}^{e}}{6 K_{B}^{e}+2 K_{G}^{e}}$

Burada $K_{u}$ ve $K^{\prime}$ zeminin drenajsız ve drenajlı bulk modülünü ifade etmektedir. $v^{\prime}$ drenajlı $v_{u}$ ise $(0.495)$ drenajsı Poisson oranını göstermektedir.

\section{MODEL SANRTIFÜJ DENEYI}

Yüksek modüllü kolonların sıvılaşabilir zeminler içeresindeki iyileştirmeye olan etkisini incelemek için [21] tarafından 4 adet model santrifüj deneyi gerçekleştirilmiş ve bu deneyler neticesinde dinamik etkiler altında kolon ile zemin arasındaki davranış kayma gerilmeleri ve kayma şekil değiştirmeleri açısından araştırılmıştır. Santrifüj deneylerden 2 tanesi iyileştirilmemiş zemin durumunu (Model 1 ve 3) diğer ikisi ise iyileştirilmiş zemin durumunu (Model 2 ve 4) yansıtmaktadır. Bu çalışma kapsamında, UBC3D-PLM modelin iyileştirilmemiş bir zeminin sıvılaşma davranışını ne ölçüde modelleyebildiğini gösterebilmek için Model 1 santrifüj deneyi sayısal olarak modellenmiş ve zeminlerin sıvılaşma davranışı incelenmiştir. Santrifüj deneyinde iç boyutları $0.38 \mathrm{~m}$ uzunluk, $0.20 \mathrm{~m}$ genişlik, $0.21 \mathrm{~m}$ derinlikte olan bir laminer kutu kullanılmıştır ve deneyler 50 g'lik bir ivme altında gerçekleştirilmiştir. Deneylerde zemin modeli en üstte $2 \mathrm{~m}$ kalınlığında ve rölatif sıkılığı $\mathrm{D}_{\mathrm{r}} \approx 60 \%$ olan orta sıkı Monterey kumu, ortada $6 \mathrm{~m}$ kalınlığında gevşek Nevada kumu 
$\left(\mathrm{D}_{\mathrm{r}} \approx 40 \%\right)$ ve en altta ise $2 \mathrm{~m}$ kalınlı̆̆ında sıkı Monterey kumu $\left(\mathrm{D}_{\mathrm{r}} \approx 90 \%\right)$ olacak şekilde oluşturulmuştur. Model deneye ait görünüm Şekil l'de gösterilmektedir. Deneyde su seviyesi zemin yüzeyinden $1.5 \mathrm{~m}$ kadar aşağıda olacak şekilde ayarlanmıştır. Deprem hareketi olarak 1999 Chi-Chi depreminin farklı ivme değerleri kullanılarak deneyler gerçekleştirilse de bu çalışma içerisinde sadece TCU078 EW istasyonundan elde edilen ve $0.54 \mathrm{~g}$ maksimum ivmeye sahip ( $\mathrm{a}_{\text {maks }}$ ) kayıt kullanılarak deneysel ve sayısal analizlerin karşılaştırılması yapılmıştır (Şekil 2). Model deneyde boşluk suyu basıncı ölçümlerini alabilmek için gevşek sıvılaşabilir zemin tabakası içerisine $\mathrm{P}_{1}, \mathrm{P}_{2}$ ve $\mathrm{P}_{3}$ olmak üzere 3 adet boşluk suyu basıncı ölçer yerleştirilmiştir. Buna ek olarak, derinlik boyunca zamana bağlı ivme değişimlerini elde edebilmek için ivmeölçerler yerleştirilmiştir $\left(\mathrm{a}_{1-8}\right)$. Aynı zamanda deprem yükleri altında zemin yüzeyinde oluşacak oturmalarını gözlemleyebilmek için $L V_{1}, L V_{2}$ ve $L^{2} V_{3}$ adı altında 3 adet düşey deplasman ölçer kullanılmıştır. Bu ölçüm cihazı verilerinden yola çıarak deneysel ve sayısal olarak elde edilen değerlerin karşılaştırılması yapılmış ve modelin sıvılaşma davranışını ne derecede modelleyebildiği incelenmiştir.

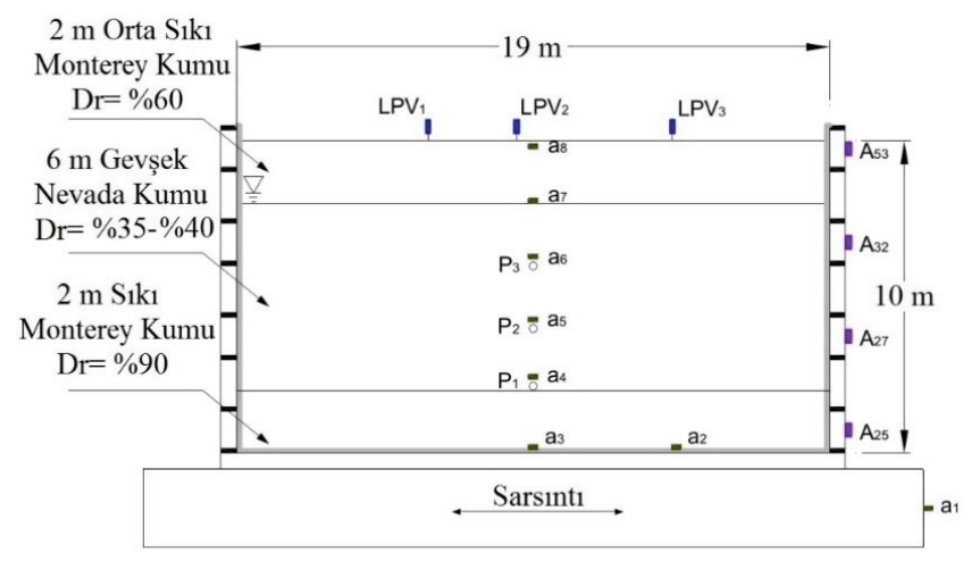

Şekil 1 - Model deneyin prototip görünümü [21]

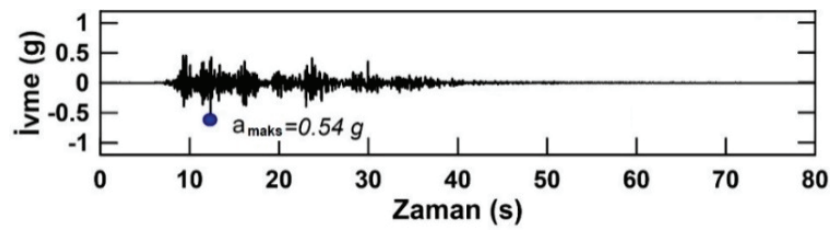

Şekil 2 - Model deneyde kullanılan deprem girdi hareketi

\subsection{Santrifüj Deneyinde Kullanılan Zeminlerin UBC3D-PLM Model ile Kalibrasyonu}

Sayısal analizlerde kullanılacak olan bünye modellerinde kalibrasyon yapılması hedeflenen sonuçlara ulaşılması açısından önemlidir. Sıvılaşma analizlerinde kullanılacak olan kalibre edilmiş zemin parametreleri, laboratuvardan elde edilen monotonik ve çevrimsel yükler altındaki davranışı tutarlılıkla yansıtması gerekmektedir. Dolayısıyla, çok karmaşık veya 
basit modelleri kullanmadan önce atılması gereken ilk adım laboratuvar deneylerinin sonuçları ile model kalibrasyonu sonrasında elde edilen gerilme izlerinin benzerliğini yakalamak olacaktır. Böylelikle, yapılacak olan analizin doğru bir şekilde yürütülmesi sağlanacaktır. Fakat, literatürde bütün zeminlerin laboratuvar deney sonuçlarını içeren bir çalışma mevcut değildir. Bu eksikliği gidermek adına bünye modeli için ihtiyaç duyulan girdi parametreleri, laboratuvar deneylerinin haricinde arazi deneylerinin yardımıyla da (SPT, CPT, vb.) bulunabilir. Burada amaç, literatürde monotonik ve çevrimsel laboratuvar deneyi sonuçları bulunamayan bazı zeminlerin ihtiyaç duyulan model girdi parametrelerini arazi deneyleri korelasyonlardan faydalanarak kolaylıkla elde etmektir. Ülkemizde en çok kullanılan arazi deneylerinin başında SPT deneyi gelmektedir. Bu deneyden elde edilecek $N_{1,60}$ değerini kullanarak model parametrelerine ulaşmak kalibrasyon aşamasında büyük kolaylıklar sağlamaktadır. $\mathrm{Bu}$ amaçla [25] tarafından UBCSAND model için bazı korelasyonlar önerilmiş ve SPT $N_{1,60}$ değerine bağlı olarak bazı model parametrelerinin yaklaşık olarak elde edilmesi hedeflenmiştir. Daha sonra [16] tarafindan bu korelasyonlar revize edilerek Plaxis UBC3D-PLM model için kullanılabilecek hale getirilmiştir. Plaxis'te UBC3D-PLM sıvılaşma modeli kullanılırken, 15 adet girdi parametresi gerekmektedir. Çizelge 1'de UBC3D-PLM model için gerekli model parametreleri ve detaylı açıklamaları yer almaktadır. Bu parametrelerden SPT $N_{1,60}$ değerine bağlı olanlar aşağıda verilen denklemler yardımiyla bulunabilir [16].

Çizelge 1 - UBC3D-PLM modelde kullanılan girdi parametreleri

\begin{tabular}{|c|c|c|c|c|}
\hline Sembol & Parametre Tanımı & Birim & Metot & Varsayılan \\
\hline$N_{1,60}$ & Düzeltilmiş SPT N değeri & - & Yerinde arazi deneyi & - \\
\hline$\phi_{c v}^{o}$ & $\begin{array}{l}\text { Sabit hacim içsel sürtünme } \\
\text { açısı }\end{array}$ & $\left({ }^{\circ}\right)$ & Üç eksenli veya DSS & - \\
\hline$\phi_{p}^{o}$ & Pik içsel sürtünme açısı & $\left({ }^{\circ}\right)$ & Üç eksenli veya DSS & - \\
\hline$c$ & Kohezyon & $\mathrm{kPa}$ & Üç eksenli veya DSS & 0 \\
\hline$k_{G}^{e}$ & Elastik kayma modülü sayısı & - & Eğri uydurma & - \\
\hline$k_{B}^{e}$ & Elastik bulk modülü sayısı & - & Eğri uydurma & - \\
\hline$k_{G}^{p}$ & Plastik kayma modülü sayısı & - & Eğri uydurma & - \\
\hline me & Elastik bulk modülü indisi & - & Eğri uydurma & 0.5 \\
\hline ne & Elastik kayma modülü indisi & - & Eğri uydurma & 0.5 \\
\hline$n p$ & Plastik kayma modülü indisi & - & Eğri uydurma & $0.4-0.5$ \\
\hline$R_{f}$ & Göçme oranı & - & Eğri uydurma & 0.9 \\
\hline $\mathrm{P}_{\mathrm{A}}$ & Atmosferik basınç & $\mathrm{kPa}$ & Standart değer & 100 \\
\hline$\sigma_{t}$ & Çekme kesimi (cut-off) & $\mathrm{kPa}$ & - & 0 \\
\hline$f_{\text {achard }}$ & Sıkılaşma faktörü & - & Eğri uydurma & 1 \\
\hline$f_{\text {acpost }}$ & Sıvılaşma sonrası faktör & - & Eğri uydurma & $0.2-1$ \\
\hline
\end{tabular}




$$
\begin{aligned}
& \phi_{p}=\phi_{c v}+\frac{N_{1,60}}{10}+\operatorname{maks}\left(0, \frac{N_{1,60}-15}{5}\right) \\
& k_{G}^{e}=21.7 \times 20 \times\left(\mathrm{N}_{1,60}\right)^{0.333} \\
& k_{B}^{e}=0.7 \times k_{G}^{e} \\
& k_{G}^{p}=k_{G}^{e} \times\left(N_{1,60}\right)^{2} \times 0.003+100 \\
& R_{f}=1.1 \times\left(N_{1,60}\right)^{-0.15}
\end{aligned}
$$

Bu çalışmada kalibre edilmiş model girdi parametreleri elde edilirken aşağıdaki adımlar takip edilmiştir:

1. UBC3D-PLM model parametreleri elde edilirken yapılması gereken ilk iş $N_{1,60}$ değerinin elde dilmesidir. Literatürde, $N_{1,60}$ değerinin rölatif sıkılığa bağlı $\left(D_{R}\right)$ olarak bulunmasıyla ilgili çok sayıda eşitlik yer almaktadır. Ancak bu çalışmada UBC3D-PLM model kullanılırken sıklıkla tercih edilen ve [28] tarafından önerilen eşitlik kullanılarak $N_{1,60}$ değeri elde edilmiştir. Burada dikkat edilmesi gereken asıl nokta kullanılan $D_{R}$ 'ye bağlı formülden ziyade elde edilen sayısal analiz sonuçlarının laboratuvar verileri ile tutarlı olmasıdır. Çünkü bu çalışmada kullanılan formülden başka herhangi bir $D_{R}$ 'ye bağlı formülden faydalanarak aşağıda ifade edilen adımları takip edip kalan parametrelere ulaşılabilir. $N_{1,60}$ değerinin kullanılmasındaki asıl amaç istenilen parametrelerin başlangıç kalibrasyon değerlerinin hızlıca elde edilmesidir. Bundan sonraki aşamalarda eğri uydurma yolunu uygulayarak parametrelerde değişikliğe gidilebilir veya sabit tutulabilir. Önemli olan kalibrasyon sonucunda elde edilen sayısal analiz sonuçları ile laboratuvar verilerini tutarlılığıdır.

2. Bu adımda Denklem 14,15 ve 17 'nin yardımıyla $k_{G}^{e}, k_{B}^{e}$ ve $R_{f}$ değerleri elde edilmiştir.

3. Modelde kullanılan kumlar temiz kum olduklarından $c$ değerleri sıfır olarak girilmiştir. Ayrıca $\sigma_{t}$ parametresi de sıfır olarak seçilmiştir.

4. $\phi_{c v}$ değeri bütün kumlarda $33^{\circ}$ olacak şekilde alınmış ve $\phi_{p}$ değerleri $\phi_{p}=\phi_{c v}+\frac{N_{1,60}}{5}$ formülü kullanılarak elde edilmiştir.

5. me, ne, $n p$ ve $\mathrm{P}_{\mathrm{A}}$ değerleri varsayılan olarak seçilmiştir.

6. Geriye kalan $k_{G}^{p}, f_{\text {achard }}$ ve $f_{\text {acpost }}$ değerleri laboratuvar direkt basit kesme (DSS) ve çevrimsel direkt basit kesme (CDSS) deneyi sonuçlarından faydalanılarak elde edilmiştir. Literatürde yer alan farklı sıkılıklardaki Nevada ve Monterey kumlarının DSS ve CDSS deney verileri kullanılarak ihiyaç duyulan parametreler elde edilmiştir. Nevada kumunun kalibrasyonu için VELACS santrifüj deneyleri kapsamında [26] tarafından gerçekleştirilen DSS ve CDSS deneyleri, Monterey kumu için [27] tarafından gerçekleştirilen laboratuvar deney verileri kullanılarak kalibrasyonlar yapılmıştır. Kalibrasyonlar sonucunda elde edilen grafikler Şekil 3 ve Şekil 4'te gösterilmiştir. 

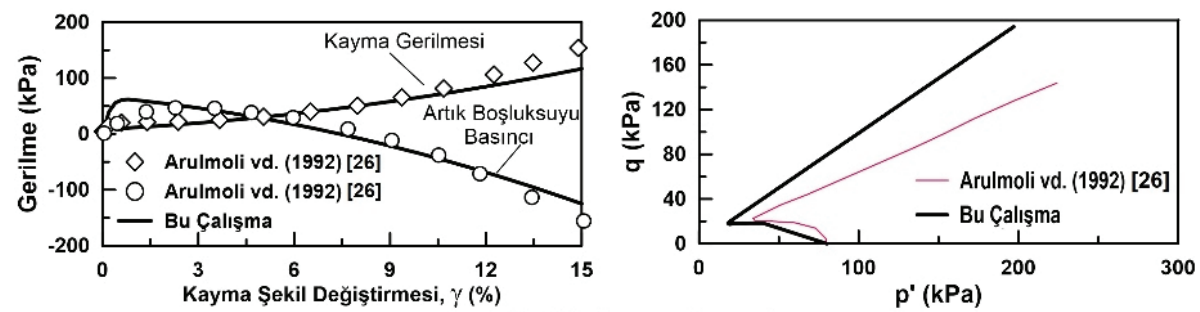

(a) DSS Deney Sonuçları
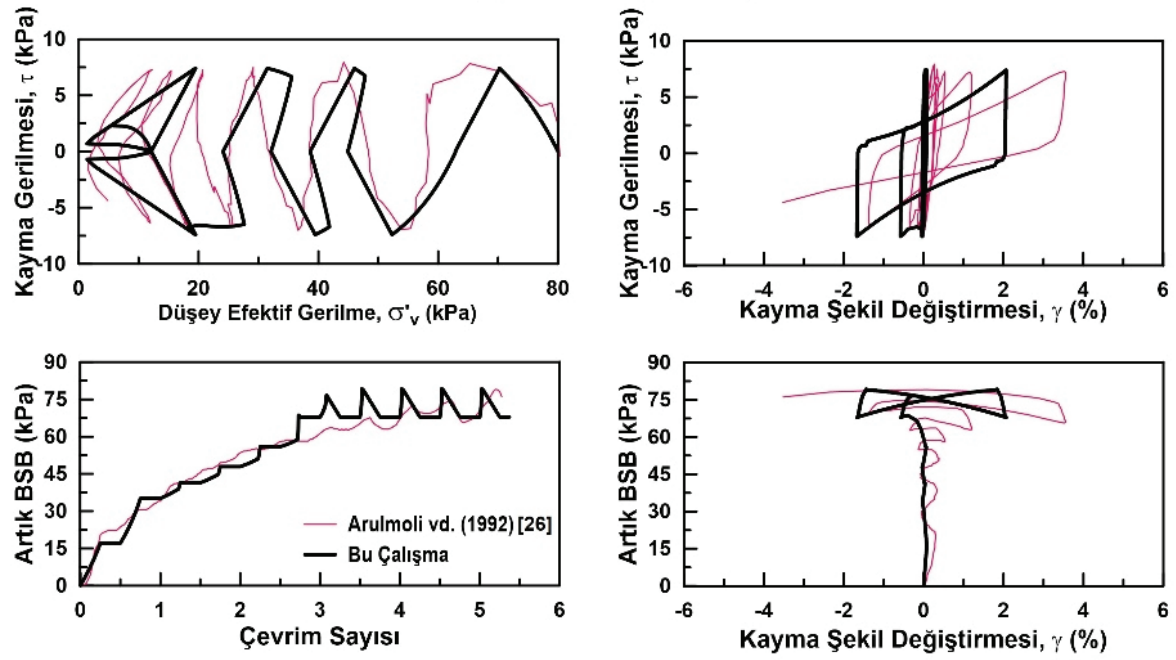

(b) CDSS Deney Sonuçları

Şekil 3 - Nevada kumu üzerinde gerçekleştirilen deneysel çalışmaların ve sayısal analizlerin sonuçlarının karşılaştırılması (a) DSS Deneyi (b) CDSS Deneyi

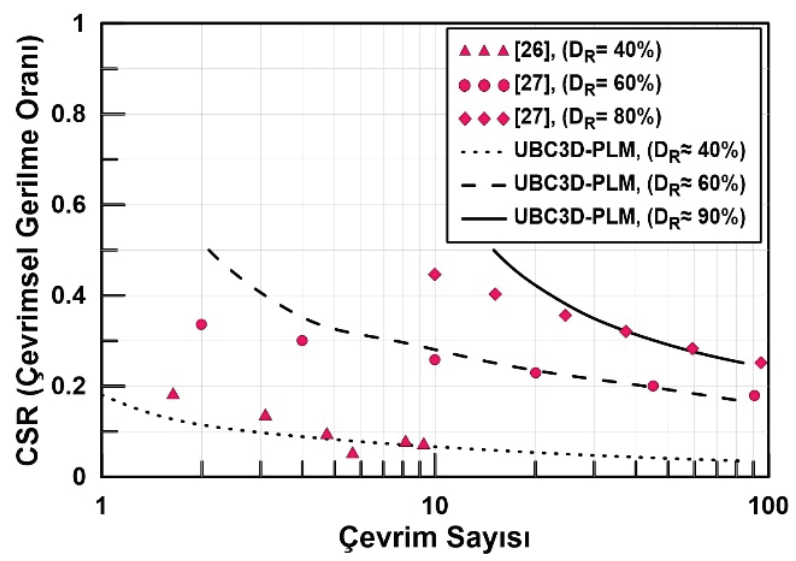

Şekil 4 - Santrifüj deneyinde kullanılan zeminlerin CSR değerlerinin çevrim sayısına bă̆lı olarak azalımı 
Yukarıda ifade edilen adımlara bağlı olarak elde edilen ve sayısal analizlerde kullanılan sıvılaşma model parametreleri Çizelge 2'de gösterildiği gibidir. Şekil 3 ve Şekil 4'te görüldüğü üzere bu kalibre edilmiş parametrelerden yola çıkarak sayısal analizlerden elde edilen gerilme izleri, laboratuvar deneylerinden elde edilen izlerle oldukça yakın benzerlik göstermektedir.

Çizelge 2 - UBC3D-PLM modelde kullanılan kalibre edilmiş zemin parametreleri

\begin{tabular}{|c|c|c|c|c|c|}
\hline Sembol & $\begin{array}{l}\text { Metot ya da } \\
\text { Formülasyon }\end{array}$ & Referans & Nevada & Monterey & Monterey \\
\hline$D_{R}(\%)$ & - & {$[21]$} & 40 & 60 & 90 \\
\hline$N_{1,60}$ & $46 \times D_{R}^{2}$ & {$[28]$} & 7.36 & 16.56 & 37.26 \\
\hline$\phi_{c v}^{o}$ & CD üç eksenli veya DSS & - & 33 & 33 & 33 \\
\hline$\phi_{p}^{o}$ & $\phi_{p}=\phi_{c v}+N_{1,60} / 5$ & - & 34.47 & 36.31 & 40.26 \\
\hline$c(\mathrm{kPa})$ & CD üç eksenli veya DSS & - & 0 & 0 & 0 \\
\hline$k_{G}^{e}$ & $21.7 \times 20 \times\left(\mathrm{N}_{1,60}\right)^{0.333}$ & {$[16]$} & 843.6 & 1105.2 & 1447.8 \\
\hline$k_{B}^{e}$ & $k_{B}^{e}=0.7 \times k_{G}^{e}$ & {$[16]$} & 590.5 & 773.63 & 1013.5 \\
\hline$k_{G}^{p}$ & Eğri uydurma & - & 180 & 1050 & 3500 \\
\hline me & Varsayılan & {$[16]$} & 0.5 & 0.5 & 0.5 \\
\hline ne & Varsayılan & {$[16]$} & 0.5 & 0.5 & 0.5 \\
\hline$n p$ & Varsayılan & {$[16]$} & 0.4 & 0.4 & 0.4 \\
\hline$R_{f}$ & $1.1 \times\left(N_{1,60}\right)^{-0.15}$ & {$[16]$} & 0.815 & 0.722 & 0.639 \\
\hline $\mathrm{P}_{\mathrm{A}}(\mathrm{kPa})$ & Standart değer & - & 100 & 100 & 100 \\
\hline$\sigma_{t}$ & - & - & 0 & 0 & 0 \\
\hline$f_{\text {achard }}$ & Eğri uydurma & - & 1 & 1 & 1 \\
\hline$f_{\text {acpost }}$ & Eğri uydurma & - & 0.2 & 0.2 & 0.2 \\
\hline
\end{tabular}

$\mathrm{Bu}$ adımlar dışında farklı yöntemler veya adımlar uygulanarak model parametreleri elde edilebilir. Bu çalışma kapsamında [16] tarafından kullanılan eşitliklerin haricinde, [29] tarafından oluşturulan bazı eşitlikler yardımıyla da kalibre edilmiş model parametreleri seçilebilmektedir.

\section{SAYISAL MODEL}

UBC3D-PLM modele ait zemin kalibrasyonları tamamlandıktan sonra santrifüj model geometrisi oluşturulmuştur. Bunun için Plaxis v.2017'de model geometrisi oluşturulurken laboratuvar deneylerinde kullanılan laminer kutunun prototip boyutları (19 m x 10 m x 10 m) 
kullanılarak analizler yapılmıştır. Statik hesap aşamalarında varsayılan model sınır koşulları (taban sınırda deplasmanlar her iki yönde tutulu $\mathrm{u}_{\mathrm{x}}=0$ ve $\mathrm{u}_{\mathrm{y}}=0$, düşey sınırlarda ise $\mathrm{x}$ yönünde deplasmanlara izin verilmezken y yönünde izin verilmiştir $u_{x}=0$ ve $u_{y} \neq 0$ ) kullanılmıştır. Dinamik analizlerde ise deprem sınır koşulları olarak düşey sınırlarda tied sınır koşullarıyla yatayda hiçbiri (none) seçeneği kullanılarak analizler yapılmıştır. Tied sınır koşulları aynı yükseklikte yer alan noktaları birbirine bağlayarak aynı deplasmanları yapmalarına olanak sağlamaktadır. Bu şekilde Plaxis'te yer alan diğer dinamik sınır koşullarının aksine laminer kutu davranışını daha gerçekçi olarak yansıtabilmektedir. Dolayısıyla, diğer dinamik sınır koşullarından olan serbest saha ve viskoz sınır koşulları bu sebepten ötürü kullanılmamıştır. Dinamik hesaplarda deprem girdi hareketini verebilmek için model tabanına x yönünde 0.01 $\mathrm{m}$ büyüklüğünde tanımlı deplasman (prescribed displacement) uygulanmıştır. Modele ait sınır koşulları ve ağ (mesh) görüntüsü Şekil 5’te gösterilmektedir.

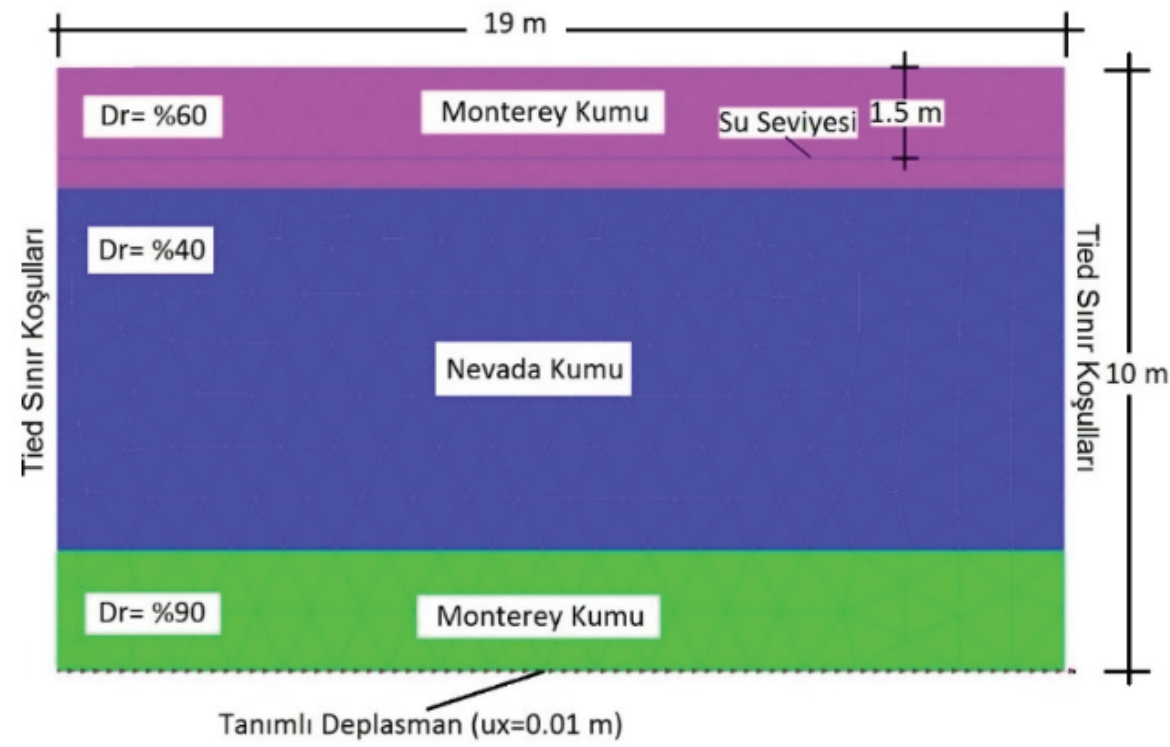

Şekil 5 - Model geometri görünümü ve mesh ă̆g

Sayısal analizlerde özellikle dinamik çözüm yaparken ağ sıklığı sonuçları önemli ölçüde etkilemektedir. Optimum düzeyde bir ağ sıklığının seçilmesi hem analizlerin tutarlı olmasına hem model içerisinde oluşacak dalgaların sağlıklı bir şekilde yayılmassına olanak sağlayacaktır. Ăg sıklığının çok fazla olması ekonomik bir çözüm olmayacak ve analiz süresini oldukça uzatacaktır. Aksine, ağ sıklığının az olması da elde edilecek sonuçların doğru olmaktan uzaklaşmasına ve daha az detaylı çözüm yapılmasına neden olacaktır. Plaxis ağ oluşturma işlemini üçgen elmanlar olacak şekilde otomatik olarak gerçekleştirmektedir. Bu çalışmada 15 düğüm noktalı üçgen elamanlar seçilerek mesh geometrisi oluşturulmuştur. Ayrıca optimum mesh aralığını belirlemek için literatürde sıklıkla kullanılan ve eleman boyları için, zeminin minimum kayma dalgası hızının girdi deprem hareketi maksimum frekans bileşenin 8 katına bölümünden küçük olması gerektiğini ifade eden eşitlik [30] 
kullanılarak, sayısal modelde eleman boyutları ortalama $0.7 \mathrm{~m}$ olarak belirlenmiş ve ağ geometrisi oluşturulmuştur.

Dinamik analizler sırasında zeminin viskoz özelliklerine, sürtünmeye ve plastik şekil değiştirmelere bağlı olarak malzeme sönümü oluşmaktadır. Kendiliğinden oluşan bu sönüm miktarı, zeminde görülen mevcut sönümden azdır ve zemin içerisindeki sönüm etkilerini gerçek olarak yansitabilmek için ekstradan sönüm etkisi uygulamak gerekmektedir [31]. Uygulanacak sönüm $(C)$ değeri, zemin kütle matrisi $(M)$ ve rijitlik matrisinin $(K)$ bir fonksiyonu olan Rayleigh sönüm değeri ile uygulanabilmektedir;

$[C]=\alpha_{R}[M]+\beta_{R}[K]$

Rayleigh sönüm formülasyonu, Rayleigh sönüm katsayıları olan $\alpha_{R}$ ve $\beta_{R}$ 'ye bağlıdır. Bu katsayıların hesabında Plaxis'te Hedef 1 ve Hedef 2 olan iki frekans değişkeni kullanılmaktadır. Hedef 1, analizlerde yer alan tüm zeminin tabakalarının doğan (temel) frekansını, Hedef 2, girdi deprem hareketi ile zeminin doğal frekansının oranını ifade etmektedir. Hedef 2 neticesinde çıkan frekans değeri kendisine en yakın tek sayıya yuvarlanarak hesaplarda kullanılmaktadır. [21] tarafından zemin doğal frekansı $2.97 \mathrm{~Hz}$. olarak verilmiştir ve Hedef 1'e karşılık gelmektedir. Deprem datasının baskın frekansı Fourier tepki spektrumundan $1.599 \mathrm{~Hz}$. olarak hesaplanmıştır ve 1.599/2.97 sonucu oran 0.538 olarak çıkmaktadır. Dolayısıyla Hedef 2, $1 \mathrm{~Hz}$. olmaktadır. Genellikle geoteknik malzemelerinin sönüm aralıkları $\% 2-\% 5$ arasında olduğu düşünülerek Rayleigh sönümü $\% 3$ alınmış ve Hedef 1 ve Hedef 2'ye karşıllk gelen $\alpha_{R}=0.282$ ve $\beta_{R}=0.0024$ değerleri kullanılarak analizler gerçekleştirilmiştir. Ayrıca, \%1, ve \%5 Rayleigh sönüm değerleri kullanılarak analizler yapılarak farklı sönüm değerlerinin sonuçlara etkileri incelenmiş fakat analiz sonuçlarında kayda değer bir değişim görülmediği için tüm analizlerde \%3 Rayleigh sönüm değeri uygulanarak analizler tamamlanmıştır. Kullanılan deprem kayıtlarının zaman adımlarının sıklığı da analiz sonuçlarının farklılaşmasına neden olabilmektedir. Bu çalışmada, [21] tarafından kullanılan deprem kaydının aralığı olan 0.01 sn. zaman aralığ1 kullanılarak yaklaşık 8000 adımda sayısal analizler gerçekleştirilmiştir.

Bu çalışmada oluşturulan sayısal modelleme aşaması genel olarak 3 adımda toplanabilir:

1. İlk adımda $\mathrm{K}_{0}$ prosedürü uygulanarak başlangıç adımı oluşturulmuştur.

2. Bu kısımda boş bir adım oluşturularak kum zeminlerin özelliklerine uygun parametreler kullanılıp Hardening Soil Model ataması yapılmıştır. Bunun yapılmasındaki amaç, modelde oluşacak başlangıç gerilme durumunu doğru bir şekilde oluşturabilmektir. UBC3D-PLM model kohezyonsuz zeminlerin dinamik davranışını modellemek için geliştirildiğinden, statik analizlerde kullanılması tavsiye edilmemekte ve başlangıç gerilme dağılımı oluşturulurken UBC3D-PLM model yerine Hardening Soil Model veya Hardening Small Strain Model'in kullanılması tavsiye edilmektedir [20].

3. Son adımda, kum zeminlere UBC3D-PLM model atanarak dinamik analiz kısmına geçilmiştir. Burada bütün analizler, Plaxiste yer alan Undrained A drenaj tipi seçeneği kullanılarak gerçekleştirilmiştir. Bu drenaj tipinde drenajsız davranış, efektif mukavemet ve rijitlik parametreleri kullanılarak analizlere yansitılmaktadır. 


\section{GENEL DEĞERLENDİRME}

Santrifüj deneyinin sayısal olarak modellenmesi sonucunda elde edilen değerler artık boşluksuyu basıncı, ivme ve deplasmanlar açısından incelenmiştir. Sayısal analizler soncunda model kutu içerisinde oluşan maksimum artık boşluk suyu basıncı oranı $\left(r_{u}\right)$ dağılımı Şekil 6'da gösterilmektedir. Buna göre \%40 sıkılığa sahip Nevada kumunun yer aldığ bölgenin büyük bölümünde $r_{u}$ değerlerinin 0.9-1.0 arasında yer aldığ1 ve sıvılaştığ1 görülürken, bazı kısımlarda ise değerlerin 0.6-0.7 bandı arasında kaldığı görülmüştür. Monterey kumunun olduğu tabakalarda ise herhangi bir sıvılaşma oluşumu görülmemiştir. Ancak, modele girdi deprem hareketinin verildiği taban bölgesinde dar bir aralıkta yüksek $r_{u}$ oluşumun meydana geldiği ve bu durumun modellemeden kaynaklandığı düşünülmektedir.

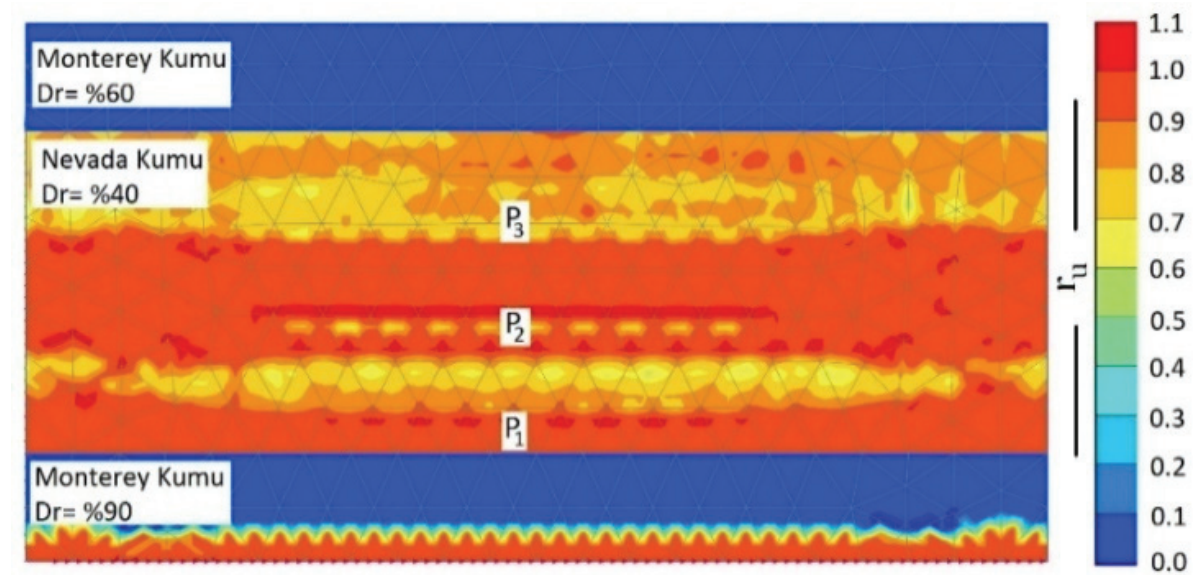

Şekil 6 - Analiz sonucunda elde edilen $r_{u}$ değerlerinin laminer kutu içerisindeki dă̆ılımı

\subsection{Artık Boşluksuyu Basıncı Değişimi}

Şekil 7a'da sayısal analizler sonucunda elde edilen artık boşluksuyu basıncı dağılımının santrifüj deneyi sonuçları ile kıyaslaması gösterilmektedir. $\mathrm{P}_{1}, \mathrm{P}_{2}$ ve $\mathrm{P}_{3}$ noktalarındaki (bkz. Şekil 1) artık boşluksuyu basıncının zamanla dağılımı incelendiğinde her 3 derinlikte deneysel veriler ile sayısal analizler sonuçları birbirine yakın çıkmıştır. Sonuçlar arasında karşılaştırma yapıldığında, deprem hareketinin başlamasıyla beraber yaklaşık 8.sn'den itibaren artık boşluksuyu basıncı oluşumunun hızlı bir şekilde artarak pik değere ulaştığ görülmüştür. $\mathrm{Bu}$ noktadan sonra laboratuvar deneylerinde 40. sn'den itibaren artık boşluksuyu basınçlarında sönümlenme olurken sayısal analizlerde artık boşluksuyu basınçlarında sönümlenme olmadan devam ettiği görülmüştür. $\mathrm{Bu}$ noktalardaki artık boşluksuyu basınçlarının zamanla mevcut düşey efektif gerilme seviyelerine ulaştığı ve zeminin sıvılaştığı görülmektedir. Bu noktada dikkat edilmesi gereken nokta, UBC3D-PLM modelin drenajsız efektif gerilme parametrelerini kullanarak çalışmasıdır. Tamamen drenajsız olarak çalışan analizlerde hacim değişiminin meydana gelmediği kabul edildiğinden UBC3D-PLM model sonucunda elde edilen artık boşluksuyu basınçlarında da herhangi bir sönüm olmamıştır. Bölüm 1'de yer alan literatür araştırmalarına bakıldığında, genellikle UBC3D-PLM modelden elde edilen artık boşluk suyu basıçlarının 
sönümlenmenin olmadığı santrifüj ya da arazi deneyleri ile kıyaslandığı görülmektedir. Kıyaslamalar neticesinde sayısal analiz ve laboratuvar verilerinin tutarlı olduğu görülmüştür. Benzer şekilde, bu çalışmada da sıvılaşma başlangıcı ve artık boşluksuyu basıncı karşılaştırmaları birbiri ile tutarlılık göstermektedir. Fakat, UBC3D-PLM modelden elde edilen artık boşluksuyu basıncı sonuçları sönümlenmenin meydana geldiği laboratuvar ya da arazi deneyleri ile kıyaslandığında, karşılaştırma sonuçlarında tutarsızlıklar oluşmaya başlamaktadır. Bu durum yukarıda ifade edildiği üzere modelin kapasitesinden kaynaklanan bir problem olarak ortaya çıkmaktadır. Burada yapılması gereken UBC3D-PLM modelin sıvılaşma başlangıcını ve artık boşluk suyu basıncı dağılımını iyi bir şekilde yansıttığını fakat artık boşluksuyu basınçlarını sönümleyemediğinin bilincinde olarak modelin kullanılmasıdır. Ek olarak, UBC3D-PLM model ile yapılan sıvılaşma analizlerinden sonra ilave bir konsolidasyon adımı uygulanarak artık boşluk suyu basınçlarının sönümlenmesi sağlanabilir. Böylelikle, Bölüm 5.2'de anlatılacak olan deplasmanlara dair tahmini bir değerin elde edilmesi sağlanabilir. Bu durum, sıvılaşma sonrası davranışı bire bir yansıtmamakla beraber sadece bir yaklaşım olarak kullanılabilir.

\subsection{Deplasman Değişimleri}

$\mathrm{LPV}_{1}, \mathrm{LPV}_{2}$ ve $\mathrm{LPV}_{3}$ deplasman ölçerlerden (bkz. Şekil 1) elde edilen deneysel sonuçlar incelendiğinde zemin yüzeyinde yaklaşık $10 \mathrm{~cm}$ civarında oturmanın meydana geldiği görülmüştür. Bu çalışmada sadece $\mathrm{LPV}_{2}$ deplasman ölçerinin verileri kullanılmış ve UBC3DPLM ile elde edilen sonuçlarla kıyaslanmıştır. Kıyas neticesinde Şekil 7b'de görüldüğü üzere $\mathrm{LPV}_{2}$ deplasman ölçerinden elde edilen deneysel veriler ile sayısal analizler sonucunda elde edilen değerler arasında oldukça büyük farklılıklar bulunmaktadır. Beklenen bu tutarsızlığın kaynağı olarak önceki bölümde anlatıldığı üzere modelin artık boşluksuyu basıncını sönümleyememesinin olduğu söylenebilir. Bu ilişkiyi daha net olarak görebilmek için Şekil 8'de artık boşluksuyu basıncı ölçümlerinin ilgili noktalardaki oturma değerlerinin karşılaştırılması verilmiştir. Şekil 8'de görüldüğü üzere sayısal analiz sonuçlarında artık boşluk suyu basıncı yaklaşık 8 . sn'de birden maksimum değere ulaşmakta ve deprem kaydı boyunca stabil bir şekilde devam etmektedir. Dolayısıyla, deprem hareketinin hemen başında zemin sıkışamaz bir hal almakta ve oturmaların oluşumuna izin vermemektedir. $\mathrm{P}_{1}, \mathrm{P}_{2}$ ve $\mathrm{P}_{3}$ noktalarındaki oturma değerlerinin en fazla $0.2 \mathrm{~mm}$ civarında olduğu görülmektedir. Ayrıca, zemin yüzeyindeki yatay deplasmanlarında benzer şekilde laboratuvar verileri ile uyumlu çıkmadığı görülmektedir. Her ne kadar girdi deprem hareketine taban düzelmesi filtresi uygulansa da, sayısal analizler sonucunda yatay deplasmanlarda zamana bağlı olarak oluşan eksen kaymasının sebebi net olarak ortaya konamamıştır.

\section{3. İvme Değişimleri}

Deneysel çalışmalar sonucunda Şekil 1'de gösterilen ve derinlik boyunca yerleştirilen ivmeölçerlerden alınan ivme-zaman değişimleri sayısal analizler sonucunda elde edilen ivme-zaman değerleri ile karşılaştırılmış ve Şekil 7c'de gösterilmiştir. Burada, UBC3D-PLM model genellikle laboratuvar deneyi sonuçlarına benzer bir şekilde ivme-zaman davranış1 göstermiş̧tir. Sadece $8.0 \mathrm{~m}\left(\mathrm{a}_{4}\right)$ ve $10.0 \mathrm{~m}\left(\mathrm{a}_{3}\right)$ yerleştirilen ivmeölçerlerden alınan değerler ile sayısal analizler soncunda elde edilen değerler arasında farklılıklar bulunmaktadır. $\mathrm{Bu}$ noktalarda görüldüğü üzere, deneysel çalışma sonucunda zeminde büyütmeler meydana 
gelirken, benzer zemin büyütme etkisi sayısal analizler sonucunda elde edilememiştir. Yüzeyde oluşan maksimum ivme değerleri incelendiğinde sayısal analiz sonucunda elde edilen $a_{\text {maks }}$ değeri laboratuvar deneyi sonucuna göre yaklaşı $\% 4$ daha fazla çıkmıştır. Bunun yanında girdi deprem hareketinden $\left(\mathrm{a}_{\text {maks }}=0.54 \mathrm{~g}\right)$ ise yaklaşık $\% 54$ daha düşüktür. Sıvılaşmanın olmadığı sıkı ve orta sıkı kum katmanlarında ivme değerleri genellikle yüksek değerlerde yer alırken, sıvılaşmanın olduğu orta bölgede yaklaşık 15. sn'den itibaren ivme değerlerinin azalarak sönümlendiği görülmüştür.

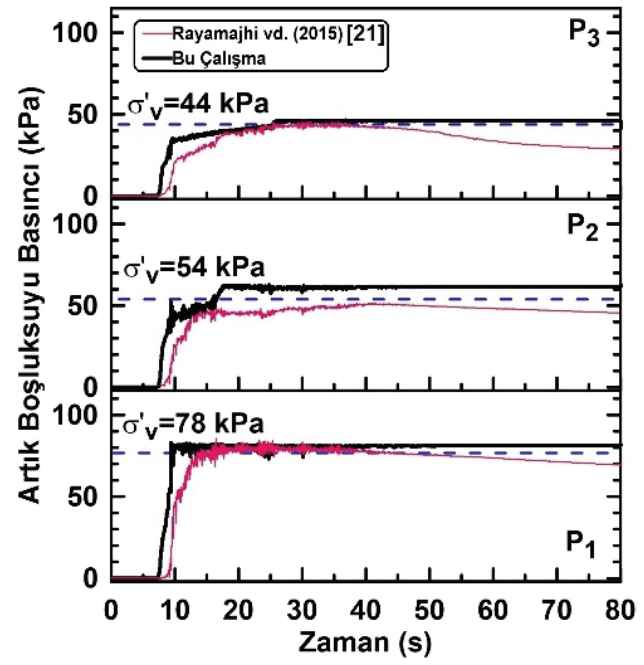

(a)

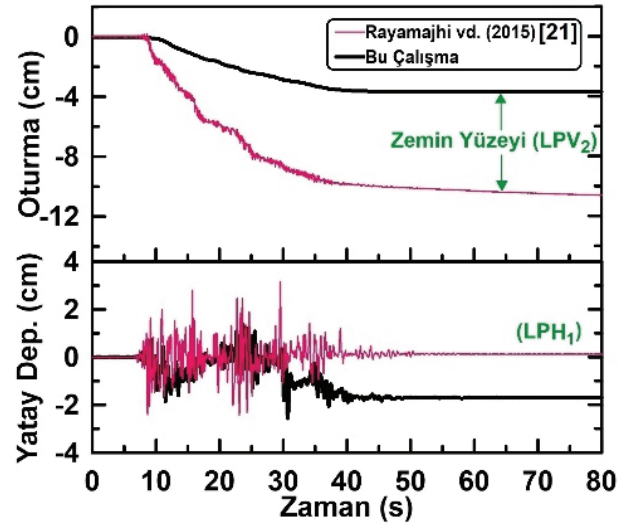

(b)

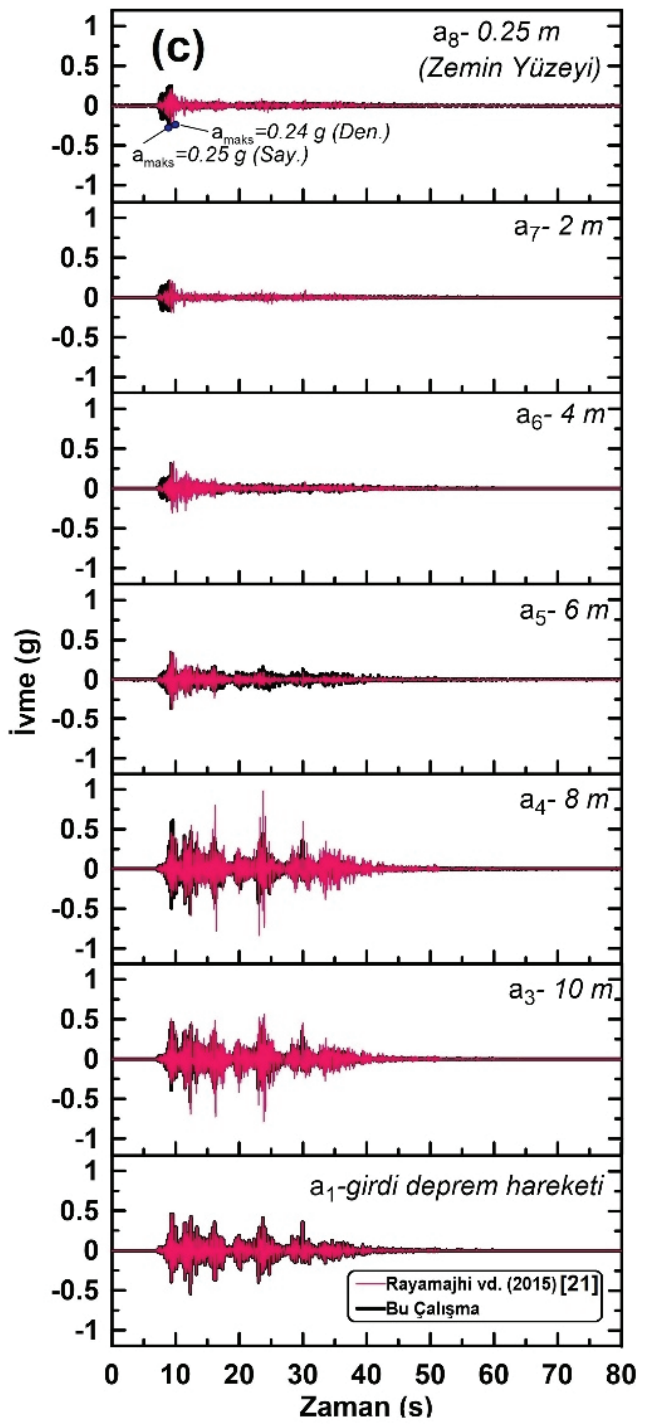

Şekil 7 - Sayısal analiz sonucunda elde edilen (a) artık boşluksuyu basıncı, (b) oturma ve

(c) ivme değişimlerinin deneysel veriler ile karşılaştırılması 

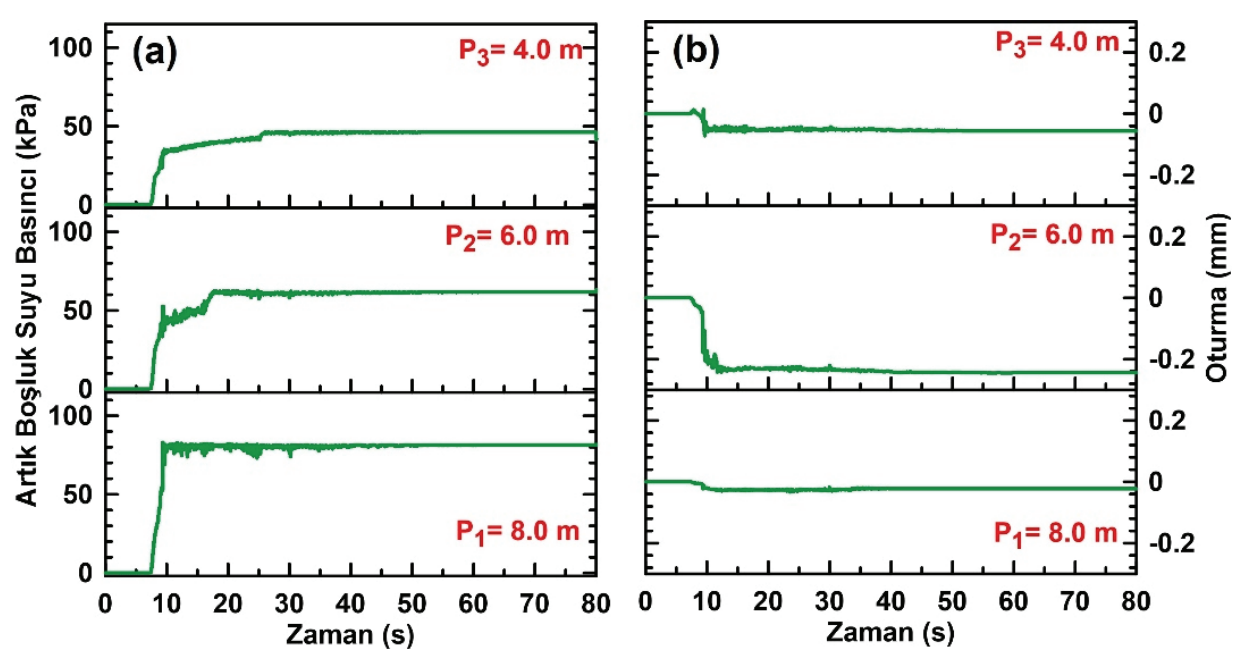

Şekil 8 - Sayısal analiz sonucunda elde edilen artık boşluksuyu basıncı ve oturma değerlerinin zamana bă̆lı olarak karşılaştırılması

\section{SONUÇLAR}

$\mathrm{Bu}$ çalışmada literatürde yer alan bir santrifüj deneyi Plaxis'te sıvılaşma modeli olan UBC3D-PLM ile modellenerek zemin sıvılaşması artık boşluksuyu basıncı, ivme ve deplasmanlar açısından değerlendirilerek modelin avantajlı ve dezavantajlı tarafları, kullanılabilirliği ve eksiklikleri incelenmiştir. Sonuçlara bakıldığında UBC3D-PLM modelin sıvılaşma başlangıcını ve artık boşluk suyu basıncı oluşumunu pik noktaya kadar tutarlı bir şekilde modellediği fakat gerçekte belirli bir süreden sonra sönümlenmeye başlayan artık boşluk suyu basınçlarının UBC3D-PLM modelin kapasitesi doğrultusunda analiz sonuçlarına yansıtamadığı görülmüştür. Artık boşluk suyu basınçları ve deplasman değişimleri birbiri ile doğrudan ilişkili olduklarından modelin sönüm kapasitesinin olmaması, elde edilen deplasman değerlerinin laboratuvardan elde edilen değerlerden oldukça farklı çıkmasına neden olmuştur ve analiz sonucunda deplasman değerlerinde arzulanan seviyelere ulaşılmamıştır. Dolaysıyla UBC3D-PLM model sayısal analizlerde, deneyde oluşan oturmaları ve yatay yer değiştirmeleri yeteri kadar ortaya koyamamıştır.

Yeni deprem yönetmeliği ile beraber, zemin sıvılaşması değerlendirilmesinde sıvılaşma tetiklenmesi riski yanında, sıvılaşma sonrası zemin mukavemeti ve rijitlik kaybı ile temel zemininde oluşabilecek yer değiştirmelerin dikkate alınması istendiğinden UBC3D-PLM model ile yapılan sıvılaşma analizleri sonucunda elde edilecek deplasman değerlerinin dikkatli bir şekilde değerlendirmesi gerekmektedir. Bu çalışmada anlatıldığı üzere sıvılaşma olan bölgedeki artık boşluksuyu basınçlarının model kapasitesi doğrultunda sönümlenmemesi ve buna bağlı olarak yeterli oturma miktarlarının elde edilememesi modelin bu konuda yetersiz olduğunu ve analizlerde bu hususun üzerinde durarak değerlendirmelerin yapılması gerektiğini ortaya koymaktadır. 
İvme değişimlerine bakıldığında ise birkaç derinlik noktası hariç zamana bağlı olarak yakın bir davranışın bulunduğu görülmüştür. Özelikle zemin yüzeyinde elde edilen maksimum genlik değerleri birbirine oldukça benzer çıkmaktadır.

UBC3D-PLM modeli kullanılabilir yapan etkenlerin başında ise SPT $\mathrm{N}_{1,60}$ değerine bağgl olarak model girdi parametrelerinin elde edilebilmesidir. Ülkemizde zemin araştırma yöntemleri olarak en çok standart penetrasyon deneyi uygulanmaktadır ve hemen hemen her projede SPT $\mathrm{N}_{1,60}$ değerleri kullanılmaktadır. Dolayısıyla, $\mathrm{SPT} \mathrm{N}_{1,60}$ değerleri kullanılarak bir zemine ait yaklaşık sıvılaşma davranışı artık boşluksuyu basıncı oluşumu ve ivmeler açısından Plaxis UBC3D-PLM modeli ile tahmin edilebilir. Yüzeyde oluşabilecek oturmalar açısından ise analiz sonuçlarına biraz daha temkinli yaklaşılarak değerlendirilmesi gerekmektedir. Buna ek olarak ilgili zeminin sıvılaşma davranışının daha iyi modellenebilmesi için mevcut imkanlar çerçevesinde zemine ait gerekli laboratuvar deneyleri yapılmalı ve bu deney sonuçları baz alınarak girdi parametrelerinin elde edilmesi tavsiye edilmektedir.

\section{Semboller}

a : Plastik potansiyel fonksiyon katsayıs1

amaks : Maksimum yüzey ivmesi

$\mathrm{a}_{1-8} \quad$ : İvmeölçerler

C : : Sönüm değeri

CDSS : Çevrimsel direkt basit kesme deneyi

CSR : Çevrimsel gerilme oranı

c' : Efektif kohezyon

$\mathrm{D}_{\mathrm{r}} \quad$ : Rölatif sıkılık

DSS : Direkt basit kesme deneyi

$d \epsilon_{v}^{p} \quad$ : Plastik hacimsel şekil değiştirme artışı

$d \lambda \quad$ : Plastik şekil değiştirme artış çarpanı

$d \gamma^{p} \quad$ : Plastik kayma şekil değiştirmesi artı̧̧1

$f_{\text {achard }}$ : Sıkılaşma faktörü

$f_{\text {acpost }}$ : Sıvılaşma sonrasını kontrol eden faktör

$\mathrm{f}_{\mathrm{m}} \quad$ : Akma yüzeyi fonksiyonu

g : Plastik potansiyel fonksiyon

hard : Gevşek zeminler için sıklaştırma doğrulama faktörü

K : Rijitlik matrisi

$K^{\prime} \quad$ : Zeminin drenajlı bulk modülü 


\begin{tabular}{|c|c|}
\hline $\mathrm{K}_{0}$ & : Sükûnet durum katsayısı \\
\hline $\mathrm{K}_{\mathrm{B}}^{\mathrm{e}}$ & : Elastik bulk modülü \\
\hline $\mathrm{K}_{\mathrm{G}}^{\mathrm{e}}$ & : Elastik kayma modülü \\
\hline $\mathrm{K}_{\mathrm{G}}^{\mathrm{p}}$ & : Plastik kayma modülü \\
\hline $\mathrm{K}_{\mathrm{G} \text {,birincil }}^{\mathrm{p}}$ & : Başlangıç plastik kayma modülü \\
\hline$K_{u}$ & : Zeminin drenajsız bulk modülü \\
\hline$K_{w}$ & : Suyun bulk modülü \\
\hline $\mathrm{k}_{\mathrm{B}}^{\mathrm{e}}$ & : Elastik bulk modülü sayısı \\
\hline $\mathrm{k}_{\mathrm{G}}^{\mathrm{e}}$ & : Elastik kayma modülü sayısı \\
\hline $\mathrm{k}_{\mathrm{G}}^{\mathrm{p}}$ & : Plastik kayma modülü sayısı \\
\hline $\mathrm{LPV}_{1,2,3}$ & : Düşey deplasman basıncı ölçerler \\
\hline$M$ & : Zemin kütle matrisi \\
\hline me & : Elastik bulk modülü indisi \\
\hline$N_{1,60}$ & : Düzeltilmiş SPT N değeri \\
\hline$n$ & : Porozite \\
\hline ne & : Elastik kayma modülü indisi \\
\hline$n p$ & : Plastik kayma modülü indisi \\
\hline $\mathrm{n}_{\mathrm{rev}}$ & : Yarım çevrim sayısı \\
\hline $\mathrm{P}_{\mathrm{A}}$ & : Atmosfer basıncı $(100 \mathrm{kPa})$ \\
\hline $\mathrm{P}_{1,2,3}$ & : Boşluksuyu basıncı ölçerler \\
\hline $\mathrm{p}^{\prime}$ & : Ortalama efektif gerilme \\
\hline$p_{w}$ & : Boşluksuyu basıncı \\
\hline $\mathrm{q}$ & : Deviatör gerilme \\
\hline$R_{f}$ & : Göçme oranı \\
\hline$r_{u}$ & : Boşluksuyu basıncı oranı \\
\hline SPT & : Standart penetrasyon deneyi \\
\hline $\mathrm{u}_{\mathrm{x}, \mathrm{y}}$ & : Yatay ve düşey deplasman \\
\hline$v^{\prime}$ & : Drenajlı Poisson oranı \\
\hline$v_{u}$ & : Drenajsız Poisson oranı \\
\hline$\alpha_{R}, \beta_{R}$ & : Rayleigh sönüm katsayıları \\
\hline
\end{tabular}




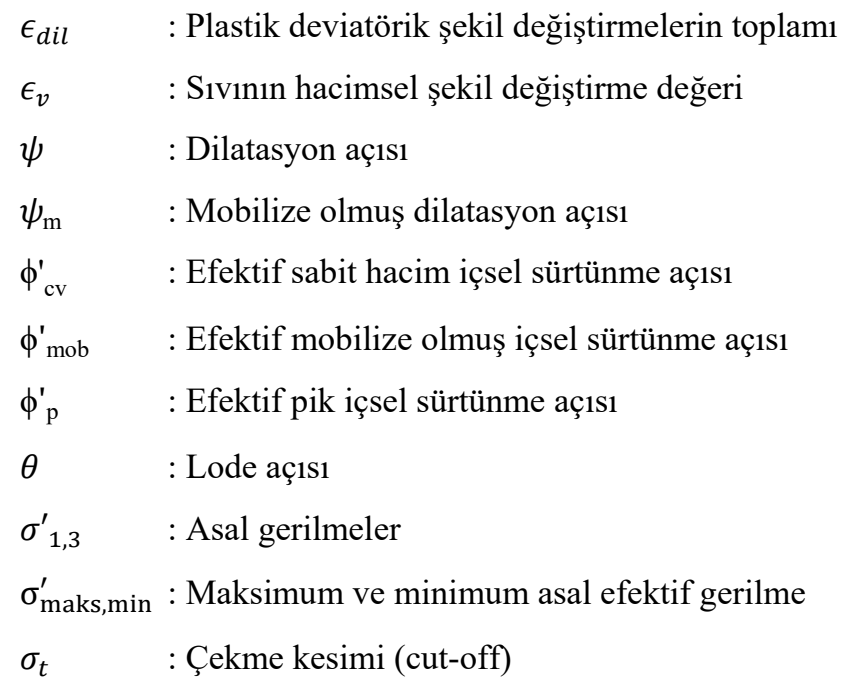

\section{Kaynaklar}

[1] Huang, Y., Wen, Z., Recent Developments of Soil Improvement Methods for Seismic Liquefaction Mitigation, Natural Hazards, 76(3), 1927-1938, 2015.

[2] Bray, J.D., Stewart, J.P., Baturay, M.B., Durgunoglu, T., Onalp, A., Sancio, R.B., Stewart, J.P., Ural D., Ansal, A., Bardet, J.B., Barka, A., Boulanger, R., Cetin, O., Erten, D., Damage Patterns and Foundation Performance in Adapazari, Earthquake Spectra, 16(S1), 163-189, 2000.

[3] Özener, P.T., Depremde Tabakalı Kum Zeminde Oluşan Sıvılaşma ve Sıvılaşma sonrası davranışın Model Deneylerle Araştırılması, Doktora Tezi, YTÜ Fen Bilimleri Enstitüsü, 2007.

[4] Youd, T.L., Liquefaction, Flow, and Associated Ground Failure, US Geological Survey Circular 688, 1-12, 1973.

[5] Ishihara, K., Liquefaction and Flow Failure During Earthquakes, Geotechnique, 43(3), 351-451, 1993.

[6] Kramer S.L., Geotechnical Earthquake Engineering, Prentice-Hall international series in civil engineering and engineering mechanics, Upper Saddle River, NJ: Prentice-Hall; 653 sayfa, 1996.

[7] Popescu R., Prevost J.H., Centrifuge Validation of a Numerical Model for Dynamic Soil Liquefaction, Soil Dynamics and Earthquake Engineering, 12(2), 73-90, 1993.

[8] Beaty, M. H., Byrne, P., An Effective Stress Model for Predicting Liquefaction Behaviour of Sand, Geotechnical Earthquake Engineering and Soil Dynamics III, ASCE Geotechnical Special Publication, 1, 766-777, 1998. 
[9] Kramer, S.L., Elgamal, A., Modeling Soil Liquefaction Hazards for PerformanceBased Earthquake Engineering, Report No: 2001/13, Pacific Earthquake Engineering Research Center, Berkeley, California, 2001.

[10] Byrne, P.M., Park, S.S., Beaty, M., Sharp, M., Gonzalez, L., Abdoun, T., Numerical Modeling of Liquefaction and Comparison with Centrifuge Tests, Canadian Geotechnical Journal, 41(2), 193-211, 2004.

[11] Andrianopoulos, K.I., Papadimitriou, A.G., Bouckovalas, G.D., Bounding Surface Plasticity Model for the Seismic Liquefaction Analysis of Geostructures. Soil Dynamics and Earthquake Engineering, 30(10), 895-911, 2010.

[12] Petalas, A., Galavi, V., Plaxis Liquefaction Model UBC3D-PLM, Plaxis Report, The Netherlands, 2013.

[13] Ramirez, J.C., Barrero, A., Chen, L., Dashti, S., Ghofrani, A., Taiebat, M., Arduino, P., Site Response in a Layered Liquefiable Deposit: Evaluation of Different Numerical Tools and Methodologies with Centrifuge Experimental Results, Journal of Geotechnical and GeoEnvironmental Engineering, 10.1061/(ASCE)GT.19435606.0001947, 2018.

[14] Sriskandakumar, S., Cyclic Loading Response of Fraser Sand for Validation of Numerical Models Simulating Centrifuge Tests, MSc Thesis, The University of British Columbia, Department of Civil Engineering, 2004.

[15] Galavi, V., Petalas, A., Brinkgreve, R.B.J., Finite Element Modelling of Seismic Liquefaction in Soils, Geotechnical Engineering Journal of the SEAGS \& AGSSEA, 44(3): 55-64, 2013.

[16] Makra, A., Evaluation of the UBC3D-PLM Constitutive Model for Prediction of Earthqueake Induced Liquefaction on Embankment Dams, MSc thesis, Delft University of Technology, 2013.

[17] Winde, H.P., Finite Element Modelling for Earthquake Loads on Dykes, MSc thesis, Delft University of Technology, 2015.

[18] van Elsäcker, W.A., Evaluation of Seismic Induced Liquefaction and Related Effects on Dynamic Behaviour of Anchored Quay Walls., MSc thesis, Delft University of Technology, 2016.

[19] Mikkelsen, A.T., Numerical Assessment on Pile Stability in Liquefiable Soil, MSc thesis, Aalborg University, 2018.

[20] Plaxis 2D Material Models Manual, 2018.

[21] Rayamajhi, D., Tamura, S., Khosravi, M., Boulanger, R.W., Wilson, D., Ashford, S., Olgun, C.G., Dynamic Centrifuge Tests to Evaluate Reinforcing Mechanisms of SoilCement Columns in Liquefiable Sand, Journal of Geotechnical Geoenvironmental Engineering, 10.1061/(ASCE)GT.1943-5606.0001298, 04015015, 2015.

[22] Puebla, H., Byrne, P.M., Phillips, R., Analysis of CANLEX Liquefaction Embankments: Prototype and Centrifuge Models, Canadian Geotechnical Journal, 34(5), 641-657, 1997. 
[23] Tsegaye, A.B., Plaxis Liquefaction Model, Delft, The Netherlands, 2010.

[24] Rowe, P.W., The Stress-Dilatancy Relation for Static Equilibrium of an Assembly of Particles in Contact, Proc. R. Soc. Lond. Ser. A, Math. Phys. Sci., 269(1339), 500-527, 1962.

[25] Beaty, M.H., Byrne, P.M., UBCSAND Constitutive Model Version 904aR" Documentation Report, UBCSAND Constitutive Model on Itasca UDM Website: http://www.itascaudm.com/media/download/UBCSand/UBCSAND_UDM_Documen tation.pdf, 2011

[26] Arulmoli, K., Muraleetharan, K.K., Hossain, M.M., Fruth, L.S., VELACS: Verification of Liquefaction Analyses by Centrifuge Studies, Laboratory Testing Program, Soil Data Report, Project No. 90-0562, The Earth Technology Corporation, Irvine, CA, 1992.

[27] Kammerer, A.M., Wu, J., Riemer, M.F., Pestana, J.M. Seed, R.B., A New MultiDirectional Direct Simple Shear Testing Database, In Proceedings, 13th World Conference on Earthquake Engineering, Vol. 2083, 2004.

[28] Idriss, I.M., Boulanger, R.W., Soil Liquefaction During Earthquakes, EERI Monograph, MNO-12, Earthquake Engineering Research Institute, 2008.

[29] Souliotis, C., Gerolymos, N., Seismic Effective Stress Analysis of Quay Wall in Liquefiable Soil: The Case History of Kobe. International journal of Geomate, 11(20), 1770-1775, 2016.

[30] Kuhlemeyer, R.L, Lysmer, J., Finite Element Method Accuracy for Wave Propagation Problems, Journal of Soil Mechanics and Foundation Devision, 99(5), 421-427, 1973.

[31] Brinkgreve, R.B.J., Swolfs W.M., Engin E., PLAXIS User's Manual, PLAXIS, The Netherlands, 2011. 